\title{
Mothers and their Adolescent Daughters Communication Regarding Pubertal Changes at Tanta City
}

\author{
Amira Mohammed Saed Mohammed*, \\ LulahAbd El-WahabAbd El-Aty Hassan**, Sina Farouk Mahdy*** \\ Pediatric Nursing Department, Faculty of Nursing, Tanta University, Egypt *. \\ Community Health Nursing Department, Faculty of Nursing, Tanta University, Egypt **. \\ Obestatric Nursing Department, Faculty of Nursing, Tanta University, Egypt $* * *$. \\ Corresponding Author:LulahAbd El-wahabAbd EL-Aty Hassan
}

\begin{abstract}
Daughters and mothers have the great amount of reciprocal disclosure in adolescent-parent family relationships. Mothers are first teachers for their daughtersregarding puberty. It's important to encouragemothers-daughters effective communication.Aim of the study:Was to assess mothers and their adolescent daughters' communication regarding pubertal changes at Tanta City.Materials and Methods: A descriptive cross-sectional study design was used in this study. Setting: This study was conducted in the governmental preparatory schools, Tanta city.Subjects: The total number of the study subjects was 400 mothers and their adolescent daughters.Data collection Tools: A structured questionnaire schedulewas prepared by the researchers.Itcomposed of two parts. Part I: for girls, that covered girls' source of knowledge about pubertal changes and menstrual hygiene, and their reaction to pubertal changes. Part II:mothers' communication and preparation of daughters for pubertal changes. Results: Slightly more than one third (35.0\%) of mothers communicate with their daughters to prepare them for puberty.The majority of the studied mothers (88\%) imposed restriction to their daughters after puberty.There were a statistically significant positive correlation between mothers' communication about puberty with daughters and their education, occupation, and number of children $(P<0.05)$. Conclusionand recommendations: About two thirds of mothers did not communicate with their daughters to prepare them for puberty. The majority of the studied mothers imposed restriction to their daughters after puberty. Friends were the main source of knowledge about puberty for more than half of the studied daughters. Educational programs aboutpubertal changesare recommended to be performed to adolescent daughters and their mothers.
\end{abstract}

Keywords: adolescent, girls, puberty, mothers, communication.

\section{Introduction}

Adolescence is a transitional stage that starts during the period from puberty to adulthood and characterized by physical and psychologicaldevelopment.Itis ordinarily associated with the teenage, whereas its physical, psychological, and cultural expressions may start earlier. For instance, puberty changes typically starts in preadolescence, especially in females ${ }^{(1-3)}$.

WHO definedadolescence as the stage in growth and development that comes next to childhood stage and before adulthood, in ages from 10 to19. It is one of the important periods in the life cycle that characterized by a rapid growth and change ${ }^{(4)}$.Adolescencemay be classified into three stages: early adolescence, which from eleven to fourteen; middle adolescence, ages from fifteen to seventeen; and late adolescence, ages from eighteen to twenty-one. Intellectual, psychological and social developmental tasks are squeezed into these years in addition to physiological growth. The main aim of these tasks is to constitute one's identity and to arrange for adulthood $^{(5)}$.

Properdealing with adolescence in community based on information from different perspectives, including biology, psychology, sociology, history, education, and anthropology. It is a stage of multiple changes involving education, training, employment and unemployment, as well as change from one living condition to another ${ }^{(6)}$.

Adolescence period is a time of change and enforcement of family relationships. Tensionis heightened between young persons and their parents duringadolescence period. During puberty,declined levels of constructive interaction and a moderaterise in the distance between the parent and adolescent are apparent. Daughters periodically feel dampen andaggrieved about their mothers over protectiveness because it endanger 
their autonomy. So far, mothers and daughters can be near and trusting ineach other more than other parentchild pair ${ }^{(7,8)}$

There is a delicatemoving that a daughter and mother typically encounter within their relationship as daughters go into adolescence. Daughters grow up from the "little baby girl" to a youth who is struggling to find herself. The strength and importance of the mother-daughter communication has been the center of comprehensiveexamining for the last years ${ }^{(9)}$.

Through years of puberty, girls start developing breasts, the hips are widen and hair starts to appear in the genital area and axilla, and they experience a harsh growth in their height; this is called as growth spurt. Occurrence of menstruation firstly is known as menarche and it occurs when girls get sexually mature. In general, menarche happens in the ages from 9 to14 years and differs on an individual base. Puberty is a period of rising challenges and stresses, whereas children adjust to their social roles. Likewise, girls who enter puberty early have more problems in social and emotional adaptation from early childhood ${ }^{(10)}$.

Unfortunately, most girls do not have correct and adequate information regarding puberty and healthy behavior related to it ${ }^{(11)}$. Therefore, knowledge on the natural trend of puberty and its problems and challenges can help successfully passing through adolescence and into adulthood and fertility ${ }^{(12)}$.

The family is the first social unit. Therefore, it plays the most important role in educating adolescents and transferring information and hygienic behaviors to them. Although each family member may have a role in teaching puberty health to adolescents, the mother plays the most prominent role in this issue and most adolescents learn hygienic behaviors from their mothers ${ }^{(13,14)}$.

Daughters and mothers have the great amount of reciprocal disclosure in adolescent-parent family relationships. Mothers are theprincipalteacher, andconsultant for their daughters; they are the mainorigin of significant andemotional assistance. It's crucial to prevent distractions as daughters and mothers listen and communicate. ${ }^{(10)}$

Daughters and mothers have the nearest tie, and it's typically because they communicate on a constantbase and in time share personal data about themselves. Conflict occurs in theparent-child relationship as parents confront the debate of choosing between whether or not to give their girlsopen and free or respectful and quietinteraction ${ }^{(16,17)}$.

Communication is essential in all interactions and relationships. Proper communication is particularly crucial when a child reaches adolescence. The girl during adolescence wants a consulter when she is growing up as she is not well-known about it. The daughter- mother communication is basic and central for the spreading of growing and learning. The tie between children and their mothers generally has been recognized as peculiar, and basic to behavior modeling and intergenerational learning ${ }^{(18,19)}$.

Aim of the study: was to assessmothers and their adolescent daughters' communication regarding pubertal changes at Tanta city.

Materials

\section{Materials And Method}

Design: A descriptive cross-sectional design was utilized in the current study.

Setting: The study was carried out in in the governmental preparatory schools in Tanta city. Tanta city include two educational districts (West \& East). Three preparatory schools were selected randomly from each district.

\section{Study subjects}

Simple random sampling was utilized to choose the schools and students. Fourhundred (400) students had been selected randomly and were willing to participate in this study. Two classrooms from each preparatory school were selected randomly(one classroom form grad I\& the other classroom from grad II, while students of grad III did not attend schools). The total number of students in each classroom was ranged from 35-40 students.

\section{Tool of data collection:A structured questionnaire schedule}

A structured questionnaire schedule was prepared by the researchers to collect the necessary data. The questionnaire composed of two parts; part I for girls, and part II for mothers. The questionnaire of girlsconsisted of socio-demographic characteristics as age, educational grad. In addition to 8 closed-ended questions that cover girls' source of knowledge about pubertal changes and menstrual hygiene, reaction to pubertal changes, social limitations they faced, causes of poor communication with mothers, and their actual personal menstrual hygiene. The questionnaire of mothers composed of socio-demographic characteristics as age, education, occupation, and number of children. Moreover, 9 close-ended questions that included mothers' communication and preparedness of girls for pubertal changes, personal hygiene and social believes about 
menstruation, causes of poor communication with girls if present, and limitations that imposed by mothers on adolescent girls.

Methods

\section{1-Obtaining approvals:}

Before carrying out the study, a written permission was obtained from Nursing Faculty, University of Tanta, directed to the Ministry of Education and subsequently official letters were directed to each director to the selected schools to get their agreement and collaboration to perform the study.

\section{2- Toolsdevelopment:}

The structured questionnaire was developed based on relevantreview of literature. The developed tool was disseminated to a committee of jury from five academic professors in community health nursing and pediatric nursing to examine its face and content validity. Thus, correcting and adjustment were done. A pilot study was done on 20 female students and their mothers to examine the tool for clarity, relevance and reliability. Data collected from pilot study of the study were excluded from the final data analysis. The questionnaire reliability was evaluated by calculating the Cronbach's alpha. Cronbach's Alpha test demonstrated that the questionnaire was reliable as it was 0.780

\section{3- The actual study.}

- Data collection continued for about six weeks from October to middle of November 2015.

- The selected students' informed consent was obtained to get involved in the study and informed them about the aim of the study and the privacy of any data given to the researchers.

- The structured questionnaire schedule (part I) that was designed for adolescent girls, the researcher distributed it to them at their classes and asked them to fill it up and return it at the same time.

- The researchers asked each participant student to take a questionnaire schedule (part I I) and fulfill it from her mother, then returned it back to the researchers in the next day.

\section{4- Statistical analysis:}

The data were entered, coded, and analyzed by SPSS (version 20). Demographic characteristics and mothers responses to the questionnaire identified by descriptive statistics (frequency numbers and percentages). Pearson correlation test was used to analyze the correlation; statistical significant was set at $\mathrm{P}$ value $<0.05$.

\section{Results}

Table (1) shows percent distribution of studied mothers regarding their socio-demographic features. The table revealed that, the age of three quarters $(75 \%)$ of the studied mothers was ranged from 35-45 years.Nearly half (49\%) of those mothers were secondary educated and $63 \%$ of them were housewives.

Table (2) shows percent distribution of mother's communication about pubertal changes with their daughters. The table demonstrated that, only about one third $(35.0 \%)$ of mothers communicate with their daughters to prepare them for puberty. Among those mothers who communicate with their daughters, more than two thirds $(71.1 \%)$ of them provide girls knowledge about puberty and menstruation from all aspects. In addition, the table illustrated that, $38.3 \%$ of mothers who did not prepare their daughters for puberty related it to lack of mother-daughter communication.

Table (3) showed percent distribution of mothers in relation to restrictions they impose on their daughters during puberty. The table revealed that, the majority of the studied mothers $(88 \%)$ imposed restriction to their daughters after puberty. Regarding the type of restriction, $72.9 \%, 58.4 \%$, and $49.9 \%$ of studied mothers imposed restriction on their daughters regarding going out home without permission, unscheduled timings, and friendship with opposite sex respectively.

Figure (1) showed percent distribution of mothers regarding hygienic practices they suggested to their daughters. It is obvious that, the high percentages $(72.0 \%$ and $55 \%)$ of mothers told their daughters about daily bath and washing pubic hair respectively. Also, the figure illustrated that slightly more than one third (34\%, $35 \%, 36 \%$, and $38 \%$ ) of mothers asked their daughters to change pads frequently, use disposable pads, change garment daily, and remove pubic hair respectively.

Table (4) shows percent distributionof studied mother in relation to their perspective on menstrual beliefs. The table reveals that slightly less than half of the mothers $(47.8 \%)$ communicate menstrual beliefs to their daughters. Moreover, slightly more than half of the mothers (52.3\%) communicate menstrual beliefs to their daughters from hygienic point of view. Whereas, $21.4 \%$ of themcommunicating menstrual beliefs from cultural point of view and $26.3 \%$ communicatingfrom practical significance point of view. Furthermore, the reaction of $21.9 \%, 50.2 \%$, and $27.9 \%$ daughter for mother reasons were get annoyed, listen carefully, and listen but showed little objection respectively. In addition about two thirds of mothers $(66.0 \%)$ views that menstrual beliefs should exist and $34.0 \%$ of them view those menstrual beliefs should not exist.

Table (5) shows percent distribution ofadolescent daughter according to their knowledge about pubertal changes. The table revealed that more than half $(59 \%)$ of the studied daughters their age was ranged from 13-15 
years. Friends were the main source of knowledge about puberty for more than half $(55 \%)$ of the studied daughters compared to $37.5 \%$ who considered their mothers is the source of knowledge. Meanwhile, the minority $(7.5 \%)$ of studied daughters depended on internet as a source of knowledge about pubertal changes. Regarding their sensation or (reaction) towards pubertal changes, $28 \%$ of them had mixed emotions of happiness, fear due responsibilities, and sadness due to restrictions.

Table (6) shows correlation between mother's communication and their socio-demographic characteristics. The table illustrated that there were a significant positive correlation between mother's communication and their education, occupation, and children number $(\mathrm{P}<0.05)$.

Table 1:Percent distribution of studied mothers regarding their socio-demographic features.

\begin{tabular}{|c|c|c|}
\hline \multirow[t]{2}{*}{ Socio-demographic features } & \multicolumn{2}{|c|}{ Studied mothers } \\
\hline & $\mathrm{No}=400$ & 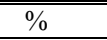 \\
\hline \multicolumn{3}{|l|}{ Age/years } \\
\hline$-\quad 25->35$ & 55 & 13.7 \\
\hline$-\quad 35->45$ & 300 & 75.0 \\
\hline$-\quad 45-55$ & 45 & 11.3 \\
\hline \multicolumn{3}{|l|}{ Education } \\
\hline - Basic education & 132 & 33.0 \\
\hline - $\quad$ Secondary & 197 & 49.0 \\
\hline - Bachelor & 67 & 17.0 \\
\hline - Master & 4 & 1.0 \\
\hline \multicolumn{3}{|l|}{ Occupation } \\
\hline - Worked mother & & 37.0 \\
\hline - $\quad$ House wife & & 63.0 \\
\hline \multicolumn{3}{|l|}{ Number of children } \\
\hline$-\quad 1-3$ & & 72.5 \\
\hline $\begin{array}{l}-\quad 4-7 \\
\end{array}$ & & 27.5 \\
\hline
\end{tabular}

Table 2: Percent distribution of mother's communication about pubertal changes with their daughters

\begin{tabular}{|c|c|c|}
\hline \multirow{2}{*}{ Mother's Communication } & \multicolumn{2}{|c|}{ Studied mothers } \\
\hline & $\mathrm{No}=400$ & $\%$ \\
\hline \multicolumn{3}{|l|}{ Communication with daughter about pubertal changes } \\
\hline - Yes & 139 & 35.0 \\
\hline - No & 261 & 65.0 \\
\hline If yes, type of preparing them for pubertal changes* & \multicolumn{2}{|c|}{$\mathrm{N}=139$} \\
\hline Providing their daughters with knowledge about puberty. & 10 & 7.1 \\
\hline Teaching their daughters about significance of menstruation. & 9 & 6.5 \\
\hline Teaching their daughters about hygienic practices during menstruation. & 12 & 8.6 \\
\hline Informing their daughters about menstrual beliefs. & 10 & 7.1 \\
\hline - $\quad$ All of the above. & 100 & 71.9 \\
\hline If no, reasons for not preparing girls & \multicolumn{2}{|c|}{$\mathrm{N}=261$} \\
\hline - Due to fear that the daughter might attain early puberty. & 61 & 23.4 \\
\hline Lack of communication & 100 & 38.3 \\
\hline Never realize the importance of preparing the daughter & 40 & 15.3 \\
\hline - Lack of time & 60 & 23.0 \\
\hline
\end{tabular}

*Multiple answers.

Table 3:Distribution of mothers in relation to restrictions they impose on the daughters during puberty.

\begin{tabular}{|c|c|c|}
\hline \multirow{2}{*}{ Daughters Restrictions } & \multicolumn{2}{|c|}{ Studied mothers } \\
\hline & $\mathrm{No}=400$ & $\%$ \\
\hline \multicolumn{3}{|l|}{ Restrictions imposed after puberty } \\
\hline - Yes & 351 & 88.0 \\
\hline$-\quad$ No & 49 & 12.0 \\
\hline If yes, types restrictions* & \multicolumn{2}{|c|}{$\mathrm{N}=351$} \\
\hline Opposite sex Friendship. & 175 & 49.9 \\
\hline _ $\quad$ Unscheduled timings & 205 & 58.4 \\
\hline - $\quad$ Coming late at home & 103 & 29.3 \\
\hline Going out with friends & 112 & 31.9 \\
\hline Watching movies with friends & 150 & 42.7 \\
\hline - $\quad$ Talking on phone for long time. & 91 & 25.9 \\
\hline - $\quad$ Staying at relatives home & 88 & 25.1 \\
\hline - Wearing of tight clothing & 119 & 33.9 \\
\hline - $\quad$ Staying at computer and internet for long time. & 158 & 45.0 \\
\hline Going out home without permission & 256 & 72.9 \\
\hline
\end{tabular}

*Multiple answers

Figure 1: Percent distribution of mothers regarding hygienic practices they suggested to their daughters 


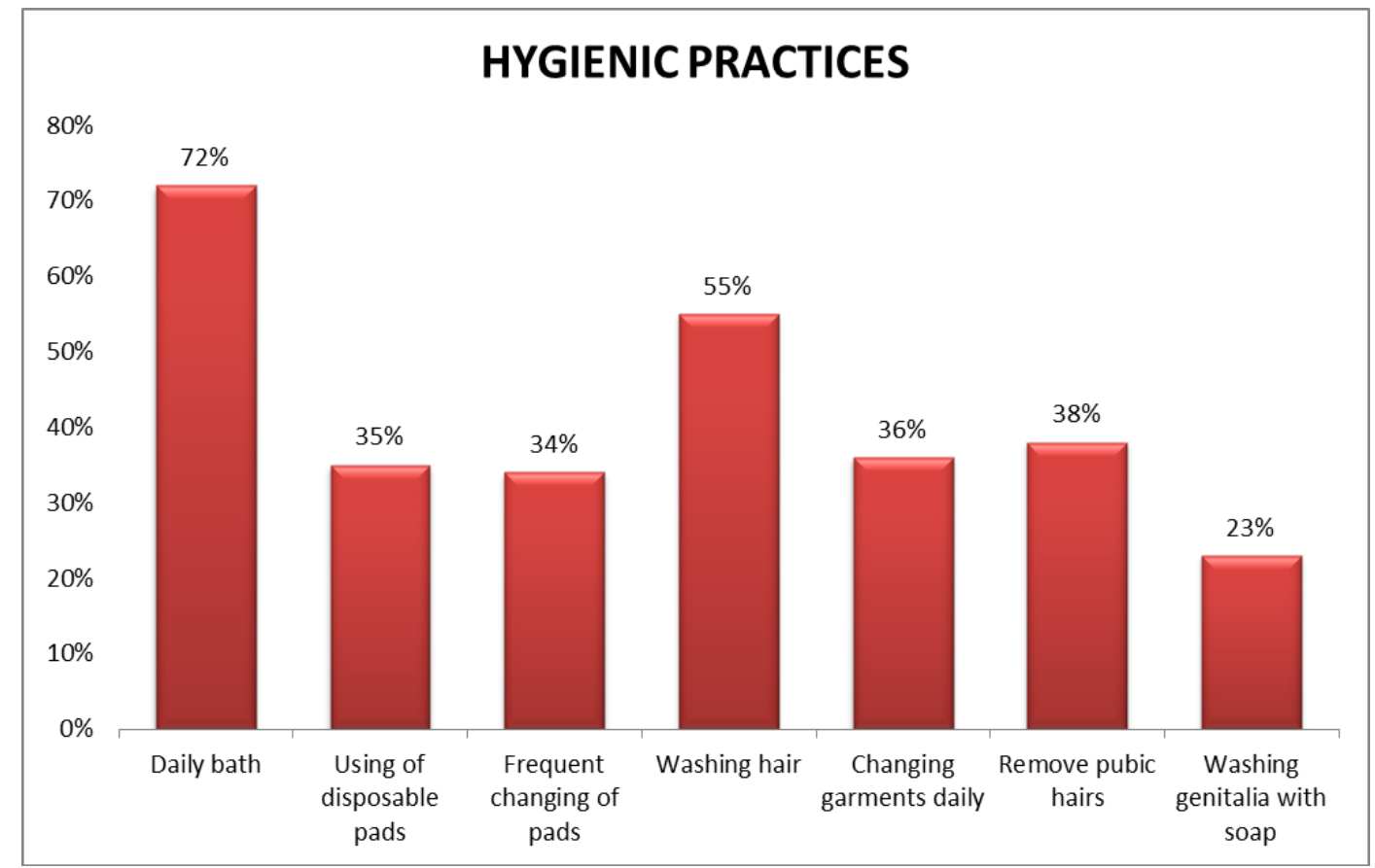

Table 4: Percent distribution of studied mother in relation to their perspective on menstrual beliefs

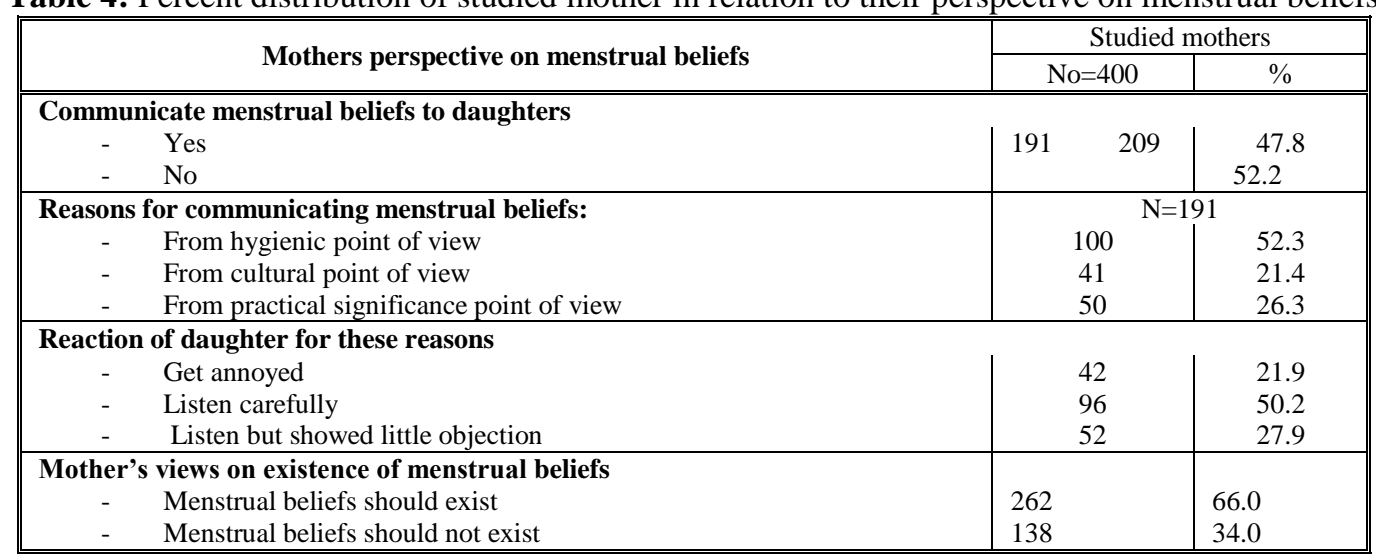

Table 5: Distribution ofadolescent daughters according to their knowledge about pubertal changes.

\begin{tabular}{|c|c|c|}
\hline \multirow[t]{2}{*}{ Knowledge about pubertal changes } & \multicolumn{2}{|c|}{ Studied daughters } \\
\hline & $\mathrm{No}=400$ & $\%$ \\
\hline \multicolumn{3}{|l|}{ Daughters age } \\
\hline$-\quad 11->13$ & 132 & 41.0 \\
\hline$-\quad 13-15$ & 268 & 59.0 \\
\hline \multicolumn{3}{|l|}{ Daughters sensation or (reaction) towards pubertal changes } \\
\hline - Happiness & 66 & 17.0 \\
\hline _ $\quad$ Fear due responsibilities & 114 & 28.5 \\
\hline - $\quad$ Sadness due to restrictions & 107 & 26.8 \\
\hline - $\quad$ All of the above & 113 & 28.0 \\
\hline \multicolumn{3}{|l|}{ Daughters sources of knowledge about pubertal changes } \\
\hline - Mother & & 37.5 \\
\hline - $\quad$ Friends & & 55.0 \\
\hline - Internet & & 7.5 \\
\hline
\end{tabular}

Table 6:Correlation between mother's communication and their socio-demographic characteristics.

\begin{tabular}{|l|c|c|c||}
\hline \multirow{2}{*}{$\begin{array}{l}\text { Mother's socio-demographic } \\
\text { characteristics }\end{array}$} & \multicolumn{3}{|c||}{ Mother's Communication } \\
\cline { 2 - 4 } & Mean \pm SD & $\mathrm{R}$ & $\mathrm{p}$-value \\
\hline \hline Age & $38.5 \pm 5$ & $-0.084-$ & .094 \\
\hline Education & $1.6 \pm 0.5$ & $-.126-$ & $.011^{*}$ \\
\hline Occupation & $1.8 \pm 0.7$ & 0.236 & $.000^{*}$ \\
\hline Number of children & $3 \pm 1$ & $-.149-$ & $.003^{*}$ \\
\hline \hline
\end{tabular}




\section{Discussion}

Transmission of health information from parent to children has been well constituted and is the current health promotion. Children health outcomes are significantly get better through the positive relation between adolescent child and parent ${ }^{(20)}$. Therefore this study was carried out to assess mother and her adolescent daughter communication regarding pubertal changes at Tanta City.Mothers as a source of information for adolescent girls can answer numerous questions related to puberty. So, the quality of the mother-daughter relationship can prevent lots of physical, psychological, and social problems and unhealthy behaviors that are rooted in adolescence ${ }^{(21)}$. The current study demonstrated that only about one third of mothers communicate with their daughters to prepare them for puberty. This may be related to variation on ages between mothers and their daughters. Also,may be due to different personalities, opinions, values, attitudes, events, and past-goals; daughters and mothers produce distinct message into their interactions. In addition, it may be attributed to lack of mother-daughter communication as reported by $(38.3 \%)$ of mothers who did not prepare their daughters for puberty, or due to lack of mother time as the working mothers are more prevalent in Egyptian society nowadays.This result is contradicted withSharma Pand Manhas S(2015)who found thatabout two thirds of mothers prepare their daughters for pubertal changes ${ }^{(22)}$. These contradicted results may be related to cultural differences between the entire populations.

The daughter-mother interactions is basic to and a fundamental for, the spreading of growing and learning. The tie between children and their mothers generally has been identified as peculiar, and basic to behavior modeling and intergenerational learning ${ }^{(18,19)}$.The majority of the studied mothers imposed restriction to their daughters after puberty such as friendship with opposite sex, going out home without permission, and wearing of tight clothing. Mothers may justify this restriction as they attemptto control their daughters to protecting the name of the family and create family stability. It is not the issuethat parents not confident their adolescent children, other than fostering responsibilities and being there when teens childrenmake wrong matter ${ }^{(16,17)}$.This explanation is in line withAshley Aet.,al (2006)who clarifies thatconflict occurs in the parentchild relationship as parents confront the debate of choosing between whether or not to give their girls open and free or respectful and quiet interaction ${ }^{(9)}$.

Regarding menstrual hygiene practices, our results showed thatthe high percentages of mothers told their daughters about daily bath and washing pubic hair. Slightly less than half of the mothers communicate about menstrual beliefs to their daughters for hygienic aspect and daughters listen carefully, the majority of mothers agree that menstrual beliefs should be exist. It may be attributed to the religious factor and its positive stress on menstrual hygiene. Also, this may be arising from the effect of the community and social customs on existing of menstrual beliefs. This explanation is in agree with Carl E et.al, (2010)who stated that social attachment is a major attribute that affect parent/adolescent connections ${ }^{(23)}$.In the same context, many Egyptian and nonEgyptian researches illustrated that, mothers were the basic source of knowledge for girls about menstruation ${ }^{(24-}$ 27).

During adolescence, matter of "attachment versus separation" and 'similarity versus differentiation' are contend by the young child to form individuality and independence ${ }^{(4)}$.The current study revealed thatthe high percentage of adolescent daughters reacted to puberty by sad and fear. It may be attributed to the responsibilities and restrictions imposed on them by their families and the society values\& traditions. In accordance, the results of Marv M and Herrera V (2014) showed that early mature girls were more likely to react to menarche with worry, fear or sadness, and were less likely to react with calm ${ }^{(28)}$.Results of Ozdemiretet., al (2010) ${ }^{(29)}$ showed that the degree to which adolescent girls demonstrate negative reactions to menarche was different than that reported by the study of Tang et., al $(20003)^{(30)}$.

Incorrect teaching of peers may result in non-reparable health and social consequences among teenagers ${ }^{(31)}$. The current research demonstratedthat friends were the main source of knowledge about pubertal changes for more than half of adolescent girls. Results of many studies worldwide are in consistent with our result as they showed that most sources of information about reproductive health of adolescents are peers and media ${ }^{(32-37)}$.On the other hand,the findings of Alavi et al. $(2009)^{(38)}$ revealed thatmothers were the most crucial source of knowledge $(73.4 \%)$ about menarche and changes in puberty process. Therefore, as mothers are the more crucial member in the family, they has the responsibility to initiate a conductive communication with their daughters about pubertal changes.

\section{Conclusion}

Only about one third of mothers communicate with their daughters to prepare them for puberty. The majority of the studied mothers imposed restriction to their daughters after puberty. Friends were the main source of knowledge about puberty for more than halfof the studied daughters. 


\section{Recommendation}

The following issues are recommended based on the results of the current study:

1- Educational programs about pubertal changesmust be performed by school health nurse to adolescent daughters and their mothers.

2- Manual handout aboutpubertal changes and personal hygiene must be disseminatedto adolescent daughters at school.

3- Mothersshould be informed about the importance of communication with her daughters about pubertal changes by nursesin primary health care settings.

\section{References}

[1] Macmillan Dictionary for Students. Macmillan, Pan Ltd. Retrieved 2010: $14 \& 456$

[2] Puberty and adolescence. MedlinePlus. 2014

[3] Roberts, Michelle. "Why puberty now begins at seven". BBC News. 2010

[4] World Health Organization. Maternal, newborn, child and adolescent health. 2016, available at http//: www. WHO.com.

[5] Dorn L D\&Biro F M. Puberty and Its Measurement: A Decade in Review. Journal of Research on Adolescence, 2011;21 (1): 180195.

[6] Steinberg L. Adolescence, $8^{\text {th }}$ ed. New York, NY: McGraw-Hill CO., 2008.273.

[7] LernerR\&Steinber L. Handbook of adolescent psychology. $3^{\text {rd }}$ ed. New York: Wiley, 2009: 187-228.

[8] Adler RB, Rosenfeld LB, Proctor RF and WinderC. "Interplay: The Process of Interpersonal Communication, Third Canadian Edition" Oxford University Press.2012: 42-45.

[9] Ashley A. Kraemer. The Tricky Transition: Communication in the Mother andAdolescent-Daughter Relationship. UW-Whitewater WisconsinN.C.U.R. 2006: 1.

[10] HokenberryM, Wilson D, Wong D. Wong's Essentials of Pediatric Nursing. $9^{\text {th }}$ ed. United States of America: Elsevier Co., 2013.

[11] Kotecha PV, Patel S, Baxi RK, Mazumdar VS, Misra S, Modi E, et al. Reproductive healthawareness among rural school going adolescents of Vadodara district. Indian J Sex Transm Dis. 2009;30(2):94-9. doi: 10.4103/0253-7184.62765. [PubMed: 21938128].

[12] Baheiraei A, Khoori E, Ahmadi F, RahimiForoushani A, Ghofranipour F. Health concerns of Iranian adolescents: protocol for a mixed methods study. Iran Red Crescent Med J. 2014;16(6):ee6715. doi: 10.5812/ircmj. 6715. [PubMed: 25068061].

[13] Chothe V, Khubchandani J, Seabert D, Asalkar M, Rakshe S, Firke A, et al. Students' perceptions and doubts about menstruation in developing countries: a case study from India. Health PromotPract. 2014;15(3):319-26. doi: 10.1177/1524839914525175. [PubMed: 24618653].

[14] Valizadeh S, Assdollahi M, Mirghafourv M and Afsari A. Educating Mothers and Girls about Knowledge and Practices toward Puberty Hygiene in Tabriz, Iran: A Randomized Controlled Clinical Trial. Iran Red Crescent Med J. 2017 February; $19(2)$ :e28593. doi: 10.5812/ircmj.28593Vangelisti AL. Handbook of family communication, New Jersey: Lawrence Erlbaum Associates. 2004.

[15] Vangelisti A.L. Handbook of family communication, New Jersey: Lawrence Erlbaum Associates. 2004.

[16] Brownell J. Listening: Attitudes, principles, and skills. Pearson Education Company, Arlington St., Boston, MA. $2006: 75$

[17] AllisonBN and Shultz JB. Parent-adolescent conflict in early adolescence. Adolescence Journal, 2004;39: 101-119.

[18] Penington B. The communicative management of connection and autonomy in african-american and european-american motherdaughter relationships. The Journal of Family Communication, 2004; 4(1): 3-34.

[19] Swanson DP,Edwards MC, SpencerMB. Adolescence: Development during a global era, Boston: Elsevier Academic Press. 2010.

[20] HynieM,Lalonde RN and Lee NS. Parent-child value transmission among Chinese immigrants to North America: the case of traditional mate preferences. Culture Divers Ethnic Minor Psycho, 2006; 12:230-44.

[21] Hutchinson MK, KahwaE, Waldron N, Hepburn Brown C, Hamilton PI, Hewitt HH, et al. Jamaican mothers' influences of adolescent girls' sexual beliefs and behaviors. J NursScholarsh. 2012;44(1):27-35. doi: 10.1111/j.1547-5069.2011.01431.x. [PubMed: 22339731]

[22] Sharma P andManhasS. Mothers' communication with daughters regarding pubertal changes: A Study in Jammu District. International Journal of Advanced Research, 2015; 3 (6): 427-432.

[23] Carl E.The challenge of mothering an adolescent daughter.Mother/adolescent daughter conflict establishes individuality and independence.Psychology Today, 2010. Available at: Health Profs .com.

[24] El-Gilany AH, Badawi K, and El-Fedawy S. Menstrual hygiene among adolescent schoolgirls in Mansoura, Egypt. Reprod Health Matters. 2005;13(26):147-52. doi: 10.1016/S0968-8080(05)26191-8. [PubMed: 16291496].

[25] Moawed S. Indigenous practices of Saudi girls in Riyadh during their menstrual period. East Mediter Health J. 2001;7(1-2):197203. [PubMed: 12596970]

[26] Kumar CM,and Babu CS. Reproductive Health Problems of Adolescent Girls between 15 and 19 in Andhra Pradesh. Pakistan Pediatr J. 2012;36(4):225-34.

[27] Aluko OO, Oluya OM, Olaleye OA, Olajuyin AA, Olabintan TF, and Oloruntoba-Oju OI. Knowledge and menstrual hygiene practices among adolescents in senior secondary schools in Ile Ife, south-western Nigeria. J Water SanitHyg Dev. 2014;4(2):24856. doi: 10.2166/washdev.2014.084.

[28] Marv M and Herrera V.Age at Menarche, Reactions to Menarche and Attitudes towards Menstruationamong Mexican Adolescent Girls. J PediatrAdolescGynecol 27 (2014) 61-66.

[29] Ozdemir F, Nazik E, and Pasinlio_glu T: Determination of the motherly reactions to adolescents' experience of menarche. J PediatrAdolescGynecol 2010; 23:153

[30] Tang CS, Yeung DY, and Lee AM: Psychosocial correlates of emotional responses to menarche among Chinese adolescent girls. J Adolesc Health 2003; 33:193

[31] Nwagwu WE. The Internet as a source of reproductive health information among adolescent girls in an urban city in Nigeria. BMC Public Health. 2007;7:354. doi: 10.1186/1471-2458-7-354. [PubMed: 18096032]

[32] Kamalikhah T, RahmatiNajarkolaei F, and Karimi M. Barriers of reproductive health education in schools. Zahedan J Res Med Sci. 2012;14(2):71-5.

[33] Malek A, AbbasiShokoohi H, Faghihi AN, Bina M, Shafiee-K, andJani AR. A study on the sources of sexual knowledge acquisition among high school students in northwest Iran. Arch Iran Med. 2010;13(6):537-42. [PubMed: 21039011] 
[34] Onyeonoro UU, Oshi DC, Ndimele EC, Chuku NC, Onyemuchara IL, Ezekwere SC, et al. Sources of sex information and its effects on sexual practices among in-school female adolescents in OsisiomaNgwa LGA, south east Nigeria. J PediatrAdolesc Gynecol. 2011;24(5):294-9. doi: 10.1016/j.jpag.2011.05.002. [PubMed: 21763163]

[35] Sieving RE, Eisenberg ME, Pettingell S, and Skay C. Friends' influence on adolescents' first sexual intercourse. Perspect Sex Reprod Health. 2006;38(1):13-9. doi: 10.1363/psrh.38.013.06. [PubMed: 16554267]

[36] BuhiER, and Goodson P. Predictors of adolescent sexual behavior and intention: a theory-guided systematic review. $J$ Adolesc Health. 2007;40(1):4-21. doi: 10.1016/j.jadohealth.2006.09.027. [PubMed: 17185201]

[37] SuleST,andUkwenyaJE. Menstrual experiences of adolescents in a secondary school. Turkish-German Gynecol Assoc. 2007;8(1):714.

[38] Alavi M, Poushaneh K, and Khosravi AA. Puberty health: knowledge, attitude and practice of the adolescent girls in Tehran, Iran. $J$ Iran Inst Health Sci Res. 2009;8(1):59-65.

Amira Mohammed Saed Mohammed. "Mothers and their Adolescent Daughters Communication Regarding Pubertal Changes at Tanta City." IOSR Journal of Nursing and Health Science (IOSR-JNHS) 6.4 (2017): 01-08. 